\title{
PEMURNIAN DAMAR MATA KUCING (Shorea Javanica) DENGAN METODE PELARUTAN
}

\section{PURIFICATION OF Damar MATA KUCING ( Shorea Javanica) WITH DISSOLVING METHOD}

\author{
Firstiando Yuda Putra, Hermawan, Azhar \\ Jurusan Teknik Kimia, Fakultas Teknik, Universitas Lampung \\ Jalan Prof. Dr. Sumantri Brojonegoro No. 1, Bandar Lampung 35145 \\ Email : hrmwn88@gmail.com
}

Dikirim 8 Oktober 2020, Direvisi 12 Maret 2021, Disetujui 29 Maret 2021

\begin{abstract}
Abstrak: Damar mata kucing merupakan salah satu produk hasil hutan Lampung. Damar mata kucing banyak diperoleh di Kabupaten Pesisir Barat dan Kabupaten Lampung Barat. Damar memiliki harga yang berbeda beda tergantung kualitas dari damar tersebut. Menurut SNI 2900.2-2012 damar mata kucing dibedakan menjadi beberapa kelas yaitu kelas A,B,C,D,E,dan Abu. Kualitas damar ditentukan oleh banyaknya kotoran, warna, dan ukuran bongkahan dari damar tersebut. Damar mata kucing yang paling bagus ialah damar yang memiliki kandungan kotoran ( tatal kayu, pasir, dan pengotor lainnya) yang paling sedikit dan memiliki warna yang bening serta memiliki ukuran bongkahan yang besar. Metode pelarutan menjadi salah satu metode yang digunakan untuk meningkatkan kualitas dari damar saat ini. Pelarutan yang dimaksud yaitu memisahkan damar dengan pengotor yang terkandung di dalam damar tersebut. Damar dapat larut pada pelarut yang bersifat non polar seperti toluena, heksana, dan kloroform dan sukar larut pada pelarut polar seperti air. Penelitian ini berkonsentrasi untuk meningkatkan kualitas damar mata kucing dengan metode Pelarutan. Penelitian ini menggunakan 3 macam pelarut yang dianggap cocok untuk melarutkan beberapa kualitas damar mata kucing hasil hutan yaitu kualitas D, E, dan abu. Ketiga jenis pelarut tersebut yaitu aseton kloroform dan heksana. Setelah itu damar mata kucing akan dilarutkan ke dalam pelarut selanjutnya damar yang sudah terlarut akan disaring dengan ukuran 200 mesh. Ini bertujuan untuk memisahkan damar dari pengotornya. Setelah itu dipanaskan dengan suhu $70{ }^{\circ} \mathrm{C}$ sampai pelarut yang digunakan menguap dan damar kembali berbentuk padatan dengan bentuk yang lebih besar.
\end{abstract}

Kata kunci: damar mata kucing, peningkatan kualitas, pelarut, penyaringan, penguapan.

\begin{abstract}
Eye's cat dammar is one of lampung's forestry product. Eye's cat dammar are widely produced in west pesisir province and west lampung province. There are variety of pricing for dammar, it's depending on the quality of them. The dammar quality is defined based on impurities quantity, color, and chunk size from the dammar. The best dammar quality are dammar with small amount of impurities (likely wood chips, sand, or other impurite), more transparent, and have a big chunk's size. Dissolving method are one of the way to increasing quality from dammar. Dissolving has a purpose to separate dammar from their impurities. Dammar can be dissolved by non-polar solvent like toluene, hexane, and chloroform and hardly dissolved by polar solvent like water. This research is focus to increasing dammar quality with dissolving method. This research use three kind of solvent to dissolve D, E, and Abu grade of dammar. Three kind of solvents are acetone, chloroform, and hexane. Dammar who dissolved by solvent are screening by the 200 mesh sieve to separate dammar from their impurities and then it's heated at $70^{\circ} \mathrm{c}$ until most of solvent are evaporated and solid-form of dammar are obtained with bigger chunk size.
\end{abstract}

Keywords: eye's cat dammar, increasing of quality, solvent ,screening, evaporating

\section{PENDAHULUAN}

Indonesia memiliki hutan alam dengan keanekaragaman tinggi yang didominasi oleh famili dipterocarpaceae. Selain menghasilkan kayu, famili dipterocarpaceae juga menghasilkan hasil hutan bukan kayu (HHBK) berupa resin damar dan minyak tengkawang. Damar yang dihasilkan kebanyakan berasal dari genus Shorea, Hopea, serta Vatica, dan spesies 
terbanyak adalah Shorea javanica K. et V. (Fintia L 2007). Pohon S. javanica menghasilkan resin damar dengan mutu yang sangat tinggi dan dikenal sebagai damar mata kucing.

Damar mata kucing merupakan salah satu produk unggulan dari hasil hutan bukan kayu di Indonesia. Getah ini berasal dari tumbuhan Shorea javanica, $S$. koordersii, Hopea dryobalanoides, $H$. intermedia, $H$. mengarawan, $H$. globosa, $H$. griffithii, $H$. micrantha, dan $H$. myrtifolia (Sumadiwangsa \& Gusmailina 2006). Getah ini telah dimanfaatkan di berbagai bidang, antara lain cat, tinta, pernis, kemenyan, dan bahan tambahan pangan (Edriana et al. 2004; Lakerveld 2007).

Damar mata kucing adalah salah satu komoditi hasil hutan bukan kayu dari golongan resin alam yang memiliki peran penting dalam komoditi ekspor Indonesia. Damar mata kucing diperoleh dari hasil penyadapan pohon Shorea javanica dengan cara menakik atau membuat lubang pada pohon, kemudian membiarkannya hingga getah keluar dan terkumpul sampai mengeras. Umumnya getah dipanen dua minggu setelah penakikan. Kegiatan ini sudah lama dilakukan oleh masyarakat sekitar hutan di daerah Lampung (Zulnely et al, 1994).

Kabupaten Pesisir Barat merupakan kabupaten yang memiliki wilayah hutan lebih dari $60 \%$ dari total luas wilayah, sehingga sektor kehutanan memiliki kontribusi yang cukup besar dalam menopang perekonomian Kabupaten Pesisir Barat. Komoditas yang menjadi unggulan dari sektor kehutanan Kabupaten Pesisir Barat hingga dikenal ke dunia Internasional adalah Damar Mata Kucing (Shorea Javanica) dengan luas areal mencapai 17.160,75 Ha dengan Produksi $6.720,20$ ton/tahun, selain itu hampir $80 \%$ produk damar mata kucing Indonesia berasal dari Kabupaten Pesisir Barat, dan digadang-gadang merupakan damar terbaik didunia yang digunakan sebagai stabilizer pada industri cat, tinta, pharmasi, kosmetik. Negara tujuan ekspor damar mata kucing meliputi : India, Jerman, Philipina, Perancis, Belgia, Uni Emirat Arab, Bangladesh, Pakistan dan Italia. Kecamatan yang memiliki luas lahan Damar Mata Kucing terbesar adalah Kecamatan Way Krui dengan luas lahan mencapai 8.510 Ha. Selain itu persebaran hasil getah damar juga banyak dihasilkan dari kecamatan Karya Penggawa dengan luas mencapai 3.569,5 Ha dan Kecamatan Pesisir Selatan dengan luas lahan mencapai $1.803 \mathrm{Ha}$ ( Buku Profil Investasi Berbasis Klaster, 2015 ).

Namun, dengan produksi damar mata kucing yang besar tersebut, dalam menangani hasil panen hanya sebatas pengangkutan, penyimpanan dan sortasi. Hal utama yang membuat kualitasnya rendah adalah banyaknya kotoran yang terkandung seperti pasir, tatal kayu, tanah dan bahan lain yang ada didalam damar mata kucing, hal ini menyebabkan hasil damar mata kucing produksi masyarakat di kabupaten Pesisir Barat kualitasnya rendah dan hal ini pula yang menyebabkan harga jual nya pun murah.

Salah satu metode yang dapat digunakan untuk memperbaiki kualitas damar mata kucing adalah metode pemanasan. Metode pemanasan prinsipnya adalah merubah bongkahan padat damar mata kucing menjadi lelehan dengan bantuan alat pemanas, pada saat meleleh damar tersebut lalu disaring.

Pada penelitian ini digunakan metode pemanasan dengan menggunakan hot plate sebagai media pemanas untuk melelehkan damar, setelah meleleh damar tersebut disaring. Damar mata kucing hasil pemurniaan dengan metode pamanasan ini diharapkan kualitasnya menjadi seperti golongan kualitas A dalam hal warna dan analisis sifat fisiknya(kadar kotoran, kadar abu, kekeruhan dalam larutan toluen, bilangan asam, titik lunak). 


\section{METODOLOGI}

\section{Bahan Penelitian}

Bahan - bahan yang digunakan pada Penelitian ini adalah Damar mata kucing kualitas A,B,C, D,E, dan Abu, Toluene, Toluene-etanol dengan perbandingan 1:1, Kloroform, Heksana, Aseton, Indikator penolftalin $1 \%$ dalam etanol, $0,1 \mathrm{~N} \mathrm{KOH}$ dalam toluene, Air

\section{Peralatan Penelitian}

Alat - alat yang digunakan pada penelitian ini adalah : Hot Plate, Penyaring Alumunium 200 Mesh, Turbidimeter, Kuvet kaca, Gelas Ukur, Buret, Erlenmeyer, Pengaduk magnetic, Softening Point Ring and Ball Apparatus, Penyangga ring, Thermometer Air Raksa, Bath dari gelas piala $800 \mathrm{ml}$, Cawan Porselen $100 \mathrm{ml}$, Aluminium foil, Palu

\section{Tahap Persiapan Alat dan Bahan Baku}

Pada tahap ini dilakukan persiapan damar mata kucing kualitas D,E, dan abu yang diperoleh dari pengepul di Kabupaten Pesisir Barat, serta menyiapkan alat - alat lain yang akan digunakan pada penelitian ini.

\section{Tahap Pembuatan Referensi}

1. Timbang sebanyak 100 gram untuk masing masing Damar Mata Kucing kualitan A, C, D, E, dan Abu.

2. Uji Warna dari ke 6 golongan tersebut dengan referensi warna yang telah dibuat.

3. Lakukan analisis uji bilangan asam, uji titik lunak, uji kekeruhan dalam toluene, dan uji kadar abu untuk ke 6 golongan tersebut.

4. Catat dan jadikan referensi untuk pembanding hasil pemurnian yang akan dilakukan.

\section{Tahap Pelarutan}

1. Siapkan 3 gelas ukur $500 \mathrm{ml}$, lalu labeli 3 ukur tersebut masing masing dengan angka 1,2,dan 3 ..
2. Tuangkan $250 \mathrm{ml}$ kloroform ke dalam gelas ukur nomor 1, $250 \mathrm{ml}$ Heksana ke dalam gelas ukur nomor 2, dan $250 \mathrm{ml}$ aseton ke gelas ukur nomor 3 .

3. Timbang $3 \times 100$ gram damar mata kucing golongan $\mathrm{D}$ di atas neraca analitik.

4. Taruh damar mata kucing yang sudah ditimbang sebelumnya ke dalam gelas ukur 1,2, dan 3 dengan berat DMK yang dimasukkan masing masing sebanyak 100 gram.

5. Tutup bagian atas ke 3 gelas ukur yang sudah berisi solvent dan damar dengan aluminium foil yang bertujuan agar pelarut tidak menguap.

6. Ambil gelas ukur nomor 1 lalu buka aluminium foilnya untuk meletakkan stirrer. Setelah stirrer sudah diletakkan tutuk kembali dengan aluminium foil.

7. Letakkan gelas ukur nomor 1 tersebut ke atas magnetic stirrer.

8. Aduk dengan kecepatan $200 \mathrm{rpm}$ sampai padatan damar melarut sempurna.

9. Lakukan kembali langkah 6 sampai 8 untuk gelas ukur nomor 2 dan 3 .

Langkah di atas dilakukan lagi dengan bahan damar mata kucing golongan $\mathrm{E}$ dan

Abu.

\section{Tahap Pelarutan}

Setelah damar mata kucing melarut sempurna, dilanjutkan ke tahap penyaringan yang bertujuan untuk memisahkan pengotor ( tanah, pasir, tatal kayu) dari damar mata kucing, adapun langkahnya sebagai berikut.

1. Siapkan peralatan filtrasi : gelas ukur $500 \mathrm{ml}$, saringan 200 mesh yang terbuat dari aluminium dan wadah $200 \mathrm{ml}$ yang terbuat dari aluminium.

2. Timbang berat saringan di atas neraca analitik.

3. Letakkan penyaring di atas wadah aluminium.

4. Tuangkan larutan DMK ke atas saringan 200 mesh, tunggu sampai 
seluruh larutan DMK melewati saringan.

5. Ambil wadah yang berisi larutan damar untuk proses penguapan.

6. Timbang berat saringan aluminium yang sudah berisi kotoran untuk mendapatkan kadar kotoran. Adapun cara menghitung berat kotoran sebagai berikut.

Berat kotoran $=(($ Berat Timbangan + Pengotor) - ( Berat timbangan sebelum digunakan).

\section{Tahap Penguapan Solvent}

Adapun langkah penguapan solvent sebagai berikut

1. Letakkan wadah aluminium yang berisi larutan ke atas hot plate.

2. Panaskan pada suhu $85^{\circ} \mathrm{C}$ hingga terbentuk padatan.

3. Setelah berbentuk padatan timbang padatan dengan neraca analitik.

4. Setelah itu letakkan ke atas hot palte kembali.

5. Ulangi langkah 3 dan 4 berulang sampai didapatkan berat dari padatan DMK tersebut konstan.

\section{Uji Kadar Kotoran}

1. Siapkan pelarut toluene sebanyak 150 $\mathrm{ml}, 2$ buah gelas beaker $500 \mathrm{ml}$, hot plate stirrer, saringan 200 mesh.

2. Ambil dan timbang sebanyak $20 \mathrm{~g}$ damar mata kucing(W) dan masukkan kedalam gelas beaker $500 \mathrm{ml}$.

3. Tuangkan $150 \mathrm{ml}$ toluena yang berguna untuk pelarut kedalam gelas beaker $500 \mathrm{ml}$ yang didalamnya sudah ada 20 g DMK, lalu letakkan gelas beaker pada hot plate lalu atur suhu $105^{\circ} \mathrm{C}$, suhu tersebut bertujuan agar pelarutan DMK didalam toluene lebih cepat. Kocok dengan magnetic stirrer hingga DMK larut sempurna.

4. Ambil gelas beaker $500 \mathrm{ml}$ yang lain yang sudah disiapka sebelumnya, letakkan saringan 200 mesh diatas gelas beaker tersebut
5. Tuangkan gelas beaker $500 \mathrm{ml}$ yang didalamnya ada larutan (campuran toluene, DMK, dan kotoran), sehingga akan didapatkan bagian tidak lolos saring yang dapat diklasifikasikan sebagai kotoran.

6. Ambil dan timbang kotoran tersebut menggunakan neraca analitik(W1).

$$
\operatorname{Kadar} \operatorname{Kotoran}(\mathrm{KK})=(\mathrm{W} 1 / \mathrm{W}) \mathrm{x}
$$
$100 \%$

Keterangan: Pengujian hanya dilakukan sekali ditiap kualitas dmk, dengan sekali pengujian tersebut dianggap sudah mewakili kadar kotoran dari salah satu dmk hasil pemurnian.

\section{Uji Kekeruhan dalam larutan toluena}

1. Siapkan pelarut toluene sebanyak 25 $\mathrm{ml}$, alat turbidimeter.

2. Tuangkan toluene $25 \mathrm{ml}$ kedalam gelas ukur $100 \mathrm{ml}$.

3. Ambil dan timbang $7 \mathrm{~g}$ damar mata kucing lalu tuangkan ke gelas ukur $100 \mathrm{ml}$ yang didalamnya sudah ada $25 \mathrm{ml}$ toluena yang bertujuan untuk melarutkan damar mata kucing tersebut.

4. Alihkan larutan ke dalam kuvet kaca, masukkan kuvet kaca ke dalam turbidimeter.

5. Baca nilai kekeruhan pada alat turbidimeter.

6. Kekeruhan dalam larutan toluene dinyatakan dalam satuan Nephelometric Turbidity Unit(NTU).

Keterangan: Pengujian hanya dilakukan sekali ditiap kualitas dmk, dengan sekali pengujian tersebut dianggap sudah mewakili nilai kekeruhan dari salah satu dmk hasil pemurnian.

\section{Uji bilangan asam}

1. Siapkan 2 kali $25 \mathrm{ml}$ toluene, 2 kali $25 \mathrm{ml}$ etanol, indicator PP, 2 kali 0,1 $\mathrm{N} \mathrm{KOH}$.

2. Campurkan $25 \mathrm{ml}$ toluene dengan 25 $\mathrm{ml}$ etanol dalam gelas ukur $100 \mathrm{ml}$ dan labeli dengan nomor 1, tutup 
dengan aluminium foil agar tidak menguap .

3. Campurkan juga $25 \mathrm{ml}$ toluene dengan $25 \mathrm{ml}$ etanol dalam gelas ukur $100 \mathrm{ml}$ dan labeli dengan nomor 2, tutup dengan aluminium foil agar tidak menguap. Jadi ada dua buah gelas ukur yang didalamnya ada campuran toluene-etanol 50 gram.

4. Ambil dan timbang $2 \mathrm{~g}$ damar mata kucing(M) dan masukkan ke dalam erlenmeyer.

5. Ambil gelas ukur nomor 1 (campuran toluene-etanol sebanyak $50 \mathrm{ml}$ ), tuangkan kedalam erlenmeyer yang didalamnya sudah ada dmk 2 gram, kocok perlahan dengan tujuan agar dmk larut.

6. lalu teteskan 5 tetes indikator PP kedalam erlenmeyer.

7. Titrasi larutan tersebut dengan $0,1 \mathrm{~N}$ $\mathrm{KOH}$ sampai warna larutan menjadi merah muda, catat volume larutan $\mathrm{KOH}$ yang diperlukan untuk menitrasi larutan(V)

8. Titrasi juga larutan toluena-etanol 50 gram yang ada di dalam gelas ukur nomor 2 dengan $0,1 \mathrm{~N} \mathrm{KOH}$, catat volume larutan $\mathrm{KOH}$ yang diperlukan untuk menitrasi, volume $\mathrm{KOH}$ ini untuk menetapkan blanko $\left(\mathrm{V}_{1}\right)$.

Bilangan asam dihitung menggunakan persamaan :

$\mathrm{BA}=\frac{(\mathrm{V} 1-\mathrm{V}) \times N \times 56,1}{M}$

Keterangan: Pengujian hanya dilakukan sekali ditiap kualitas dmk, dengan sekali pengujian tersebut dianggap sudah mewakili nilai bilangan asam dari salah satu dmk hasil pemurnian.

\section{Uji titik lunak}

1. Ambil damar mata kucing 50 gram masukkan kedalam gelas beaker 100 $\mathrm{ml}$, lalu letakkan gelas beaker keatas hot plate, atur suhu $105^{\circ} \mathrm{C}$ hingga DMK meleleh, masukan lelehan damar mata kucing ke dalam ring, selanjutnya permukaan diratakan.

2. Letakkan ring yang berisi damar mata kucing pada ring holder dan letakkan bola baja diatas damar mata kucing tersebut

3. Gelas piala $800 \mathrm{ml}$ diisi aquades 650 ml, masukkan ring beserta bola baja dan thermometer ke dalam piala. Pemanasan dilakukan sampai damar mata kucing melunak dan bola baja menyentuh plat dasar.

4. Titik lunak adalah suhu rata-rata dari hasil pembacaan pada waktu bola baja turun menyentuh plat dasar gelas piala.

Keterangan: Pengujian hanya dilakukan sekali ditiap kualitas dmk, dengan sekali pengujian tersebut dianggap sudah mewakili nilai dari salah satu dmk hasil pemurnian.

\section{Uji Kadar Abu}

1. Timbang cawan porselen(wo) menggunakan timbangan analitik.

2. Ambil dan timbang 5 gram damar mata kucing, lalu remukkan dan saring dengan saringan ukuran 100 mesh, tujuan dibuat ukuran 100 mesh agar pada proses pemanasan untuk mengabukan DMK dalam tanur lebih cepat.

3. Ambil DMK yang lolos saring 100 mesh tersebut damar mata kucing yang telah dibuat serbuk halus 100 mesh lalu letakkan kedalam cawan porselen lalu timbang(w1)

4. Masukkan cawan beserta damar mata kucing ke dalam tanur pada suhu $625^{\circ} \mathrm{C}$. Proses pemanasan didalam tanur dihentikan sampai tidak ada lagi asap yang keluar dan jika dilihat terbentuk abu di cawan dalam tanur tersebut.

5. Lalu ambil cawan dari dalam tanur, lalu timbang berat tetap(w2)

$\operatorname{Kadar} \operatorname{Abu}(\%)=\frac{(w 2-w 0)}{(w 1-w 0)} \times 100 \%$

Keterangan: Pengujian hanya dilakukan sekali ditiap kualitas dmk, dengan sekali 
pengujian tersebut dianggap sudah mewakili nilai kadar abu dari salah satu dmk hasil pemurnian.

\section{Uji Warna Menggunakan Referensi Warna}

Uji ini dilakukan untuk menetapkan DMK hasil pemurnian dari segi warna/visual akan dikategorikan.

Adapun langkah dalam uji warna ini adalah sebagai berikut :

1. Siapkan referensi warna yang telah dibuat (didalam lampiran).

2. Ambil satu DMK hasil pemurnian

3. Cocokkan DMK hasil pemurnian dengan referensi warna yang telah dibuat, perhatikan dan cocokkan.

4. Jika sudah didapatkan kecocokkan antara DMK hasil pemurnian dengan referensi warna, maka kategorikan DMK tersebut sesuai warna yang ada pada referensi warna tersebut.

5. Ulangi langkah untuk DMK hasil pemurnian yang lainnya.

Keterangan: Pengujian hanya dilakukan sekali ditiap kualitas dmk, dengan sekali pengujian tersebut dianggap sudah mewakili warna dari salah satu dmk hasil pemurnian.

\section{Uji GC/MS}

Uji ini dilakukan untuk mengetahui komponen kimia dari damar mata kucing. Uji ini dilakukan menggunakan alat GC/MS. Adapun DMK yang akan diujikan adalah :

1. DMK Kualitas D, E, dan Abu referensi.

DMK hasil proses pemurnian yang terbaik secara hasil analisis atau uji warna, analisis kadar kotoran, titik lunak, kadar abu, bilangan asam, kekeruhan dalam larutan toluene atau yang paling signifikan peningkatan kualitasnya.

\section{HASIL DAN PEMBAHASAN}

Berikut adalah data hasil penelitian pemurnian damar mata kucing menggunakan metode pemanasan:

Tabel 1. Hasil Analisis kadar kotoran DMK Referensi

\begin{tabular}{ll}
\hline Kualitas DMK & Kadar kotoran \\
\hline A & \\
B & $0,06 \%$ \\
C & $0,06 \%$ \\
D & $1,75 \%$ \\
E & $2,9 \%$ \\
Abu & $10,6 \%$ \\
\hline
\end{tabular}

Tabel 2. Hasil analisis kekeruhan dalam toluena DMK Referensi

\begin{tabular}{ll}
\hline $\begin{array}{l}\text { Kualitas } \\
\text { DMK }\end{array}$ & $\begin{array}{l}\text { Nilai kekeruhan } \\
\text { (NTU) }\end{array}$ \\
\hline A & 39,8 \\
B & 39,8 \\
C & 156 \\
D & 169 \\
E & 193 \\
Abu & 370 \\
\hline
\end{tabular}

Tabel 3. Hasil analisis bilangan asam DMK Referensi

\section{Kualitas DMK Bilangan asam}

\begin{tabular}{ll}
\hline A & 25,2 \\
B & 25,2 \\
C & 30,8 \\
D & 32,2 \\
E & 33,6 \\
Abu & 37,8 \\
\hline
\end{tabular}


Tabel 4. Analisis Bilangan Asam DMK Referensi

\begin{tabular}{cc}
\hline $\begin{array}{l}\text { Kualitas } \\
\text { DMK }\end{array}$ & Bilangan asam \\
\hline A & 25,2 \\
B & 25,2 \\
C & 25,2 \\
D & 25,2 \\
E & 25,2 \\
Abu & 25,2 \\
\hline
\end{tabular}

Tabel 5. hasil analisis titik lunak DMK Referensi

\begin{tabular}{lrrl}
\hline Kualitas & \multicolumn{3}{c}{ Titik lunak $\left({ }^{\mathbf{0}} \mathbf{C}\right)$} \\
DMK & 1 & 2 & Rata-rata \\
\hline A & 90.0 & 90.5 & 90.3 \\
B & 90.0 & 90.5 & 90.3 \\
C & 90.0 & 92.0 & 91.0 \\
D & 91.0 & 92.0 & 91.5 \\
E & 95.0 & 94.5 & 95.0 \\
Abu & 97.0 & 97.5 & 97.3 \\
\hline
\end{tabular}

Tabel 6. hasil analisis kadar abu DMK Referensi

\begin{tabular}{ll}
\hline Kualitas DMK & Kadar abu \\
\hline A & $6 \%$ \\
B & $6 \%$ \\
C & $7,8 \%$ \\
D & $8,03 \%$ \\
E & $18 \%$ \\
$\mathrm{Abu}$ & $18,75 \%$ \\
\hline
\end{tabular}

Tabel 7. Hasil Analisis Warna DMK Hasil Proses Referensi

\begin{tabular}{|l|l|l|c|}
\hline $\begin{array}{l}\text { Kuali } \\
\text { tas } \\
\text { DMK }\end{array}$ & $\begin{array}{l}\text { Nom } \\
\text { or } \\
\text { war } \\
\text { na }\end{array}$ & $\begin{array}{l}\text { Masu } \\
\text { k } \\
\text { golon } \\
\text { gan } \\
\text { warn } \\
\text { a }\end{array}$ & \\
\hline A & 4 & $\begin{array}{l}\text { Kuni } \\
\text { ng }\end{array}$ & \\
\hline
\end{tabular}

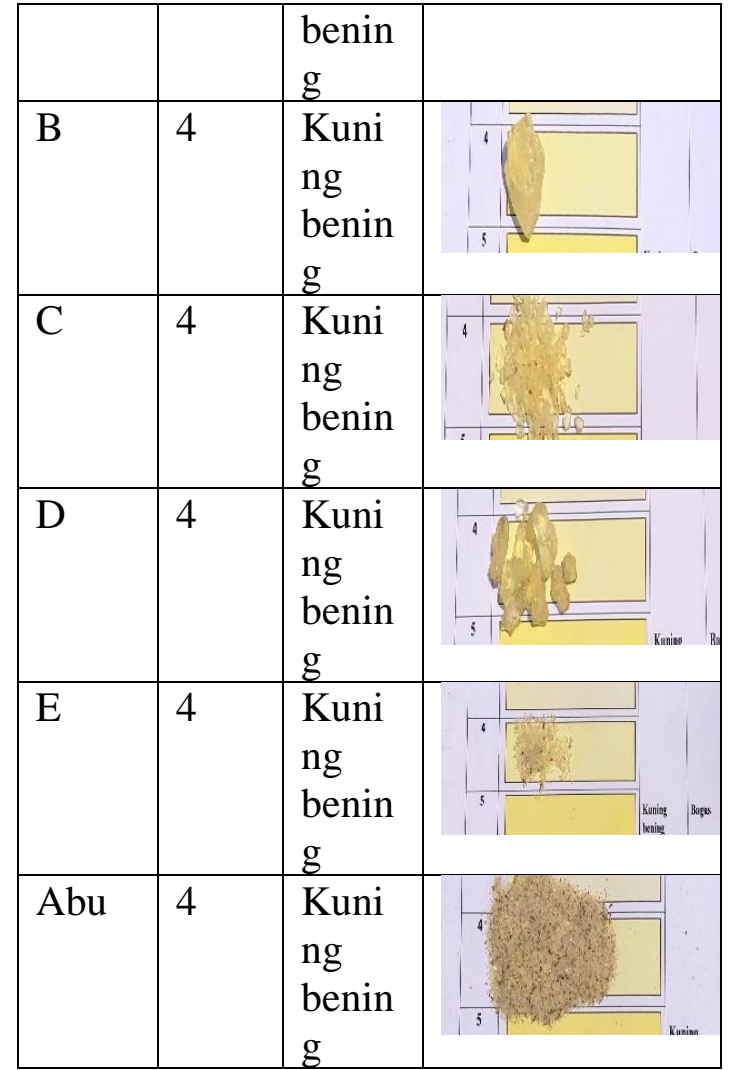

Tabel 8. Hasil Analisis Kadar Kotoran DMK Hasil Proses Pemurnian

\begin{tabular}{lll}
\hline Kualitas & Pelarut & $\begin{array}{l}\text { Kadar } \\
\text { KMK }\end{array}$ \\
\end{tabular}

\begin{tabular}{lll}
\hline $\mathrm{D}$ & Heksana & $34 \%$ \\
$\mathrm{D}$ & Aseton & $39 \%$ \\
$\mathrm{D}$ & Klorofom & $12 \%$ \\
$\mathrm{E}$ & Heksana & $37 \%$ \\
$\mathrm{E}$ & Aseton & $41 \%$ \\
$\mathrm{E}$ & Klorofom & $17 \%$ \\
$\mathrm{Abu}$ & Heksana & $44 \%$ \\
$\mathrm{Abu}$ & Aseton & $42 \%$ \\
$\mathrm{Abu}$ & Klorofom & $20 \%$ \\
\hline
\end{tabular}

Tabel 9. pencatatan rendemen dari bagian lolos saring(RENDEMEN)

\begin{tabular}{llr}
\hline $\begin{array}{l}\text { Kualitas } \\
\text { DMK }\end{array}$ & Pelarut & $\begin{array}{l}\text { Rendemen } \\
\text { (B/A)x100\% }\end{array}$ \\
\hline D & n-Heksana & $65,92 \%$ \\
D & Aseton & $60,80 \%$ \\
D & Klorofom & $87,12 \%$ \\
E & n-Heksana & $62,75 \%$ \\
E & Aseton & $59,18 \%$ \\
E & Klorofom & $82,47 \%$ \\
Abu & n-Heksana & $55,41 \%$ \\
Abu & Aseton & $57,35 \%$ \\
Abu & Klorofom & $79,45 \%$ \\
\hline
\end{tabular}


Tabel 10. Analisis kadar kotoran pada DMK hasil proses pemurnian

\begin{tabular}{lll}
\hline $\begin{array}{l}\text { Kualitas } \\
\text { DMK }\end{array}$ & $\begin{array}{l}\text { Jenis } \\
\text { Pelarut }\end{array}$ & $\begin{array}{l}\text { Kadar } \\
\text { kotoran }\end{array}$ \\
\hline D & Heksana & $0,16 \%$ \\
D & Aseton & $0,146 \%$ \\
D & Klorofom & $0,01265 \%$ \\
E & Heksana & $0,17 \%$ \\
E & Aseton & $0,164 \%$ \\
E & Klorofom & $0,07 \%$ \\
Abu & Heksana & $0,38 \%$ \\
Abu & Aseton & $0,187 \%$ \\
Abu & Klorofom & $0,153 \%$ \\
\hline
\end{tabular}

Tabel 11. Hasil analisis kekeruhan dalam larutan toluene DMK hasil proses pemurnian

\begin{tabular}{lll}
\hline $\begin{array}{l}\text { Kualitas } \\
\text { DMK }\end{array}$ & $\begin{array}{l}\text { Jenis } \\
\text { Pelarut }\end{array}$ & $\begin{array}{l}\text { Nilai } \\
\text { kekeruhan } \\
\text { (NTU) }\end{array}$ \\
\hline D & Heksana & 14,72 \\
D & Aseton & 83,89 \\
D & Klorofom & 54,52 \\
E & Heksana & 21,42 \\
E & Aseton & 177,72 \\
E & Klorofom & 76,22 \\
Abu & Heksana & 95,02 \\
Abu & Aseton & 324,02 \\
Abu & Klorofom & 102,22 \\
\hline
\end{tabular}

Tabel 12. Hasil Analisis Bilangan Asam DMK Hasil Proses Pemurnian

\begin{tabular}{lll}
\hline $\begin{array}{l}\text { Kualitas } \\
\text { DMK }\end{array}$ & Pelarut & $\begin{array}{l}\text { Bilangan } \\
\text { asam }\end{array}$ \\
\hline D & Heksana & 42,075 \\
D & Aseton & 36,465 \\
D & Klorofom & 49,087 \\
E & Heksana & 36,465 \\
E & Aseton & 28,050 \\
E & Klorofom & 49,087 \\
Abu & Heksana & 47,685 \\
Abu & Aseton & 39,270 \\
Abu & Klorofom & 50,490 \\
\hline
\end{tabular}

*Berat DMK yang digunakan :@2 gr
Tabel 13. Hasil Analisis Titik Lunak DMK Hasil Proses Pemurnian

\begin{tabular}{lllll}
\hline $\begin{array}{l}\text { Kualitas } \\
\text { DMK }\end{array}$ & Pelarut & \multicolumn{3}{l}{ Titik lunak $\left({ }^{\circ} \mathbf{C}\right)$} \\
& & 1 & 2 & $\begin{array}{l}\text { Rata- } \\
\text { rata }\end{array}$ \\
\hline D & Heksana & 86 & 88.5 & 87.25 \\
D & Aseton & 83 & 83 & 83 \\
D & Klorofom & 74 & 75 & 74.5 \\
E & Heksana & 90 & 91.5 & 90.75 \\
E & Aseton & 84.5 & 84.5 & 84.5 \\
E & Klorofom & 79.5 & 80.5 & 80 \\
Abu & Heksana & 90 & 91.5 & 90.75 \\
Abu & Aseton & 85 & 85.5 & 85.75 \\
Abu & Klorofom & 86.5 & 86.5 & 86.5 \\
\hline
\end{tabular}

Tabel 14. Hasil Analisis Titik Lunak DMK Hasil Proses Pemurnian

\begin{tabular}{lll}
\hline $\begin{array}{l}\text { Kualitas } \\
\text { DMK }\end{array}$ & Pelarut & $\begin{array}{l}\text { Kadar abu } \\
(\boldsymbol{\%})\end{array}$ \\
\hline D & Heksana & $6,6705 \%$ \\
D & Aseton & $5,3834 \%$ \\
D & Klorofom & $5,0630 \%$ \\
E & Heksana & $6,9342 \%$ \\
E & Aseton & $7,4200 \%$ \\
E & Klorofom & $5,2799 \%$ \\
Abu & Heksana & $7,2361 \%$ \\
Abu & Aseton & $8,7571 \%$ \\
Abu & Klorofom & $6,6192 \%$ \\
\hline
\end{tabular}

Tabel 15. Hasil Uji Warna Pada DMK Hasil Proses Pemurnian

\begin{tabular}{|l|l|l|}
\hline $\begin{array}{c}\text { Kualitas } \\
\text { DMK }\end{array}$ & Solvent & Photo \\
\hline D & Heksana & \\
& & \\
\hline
\end{tabular}




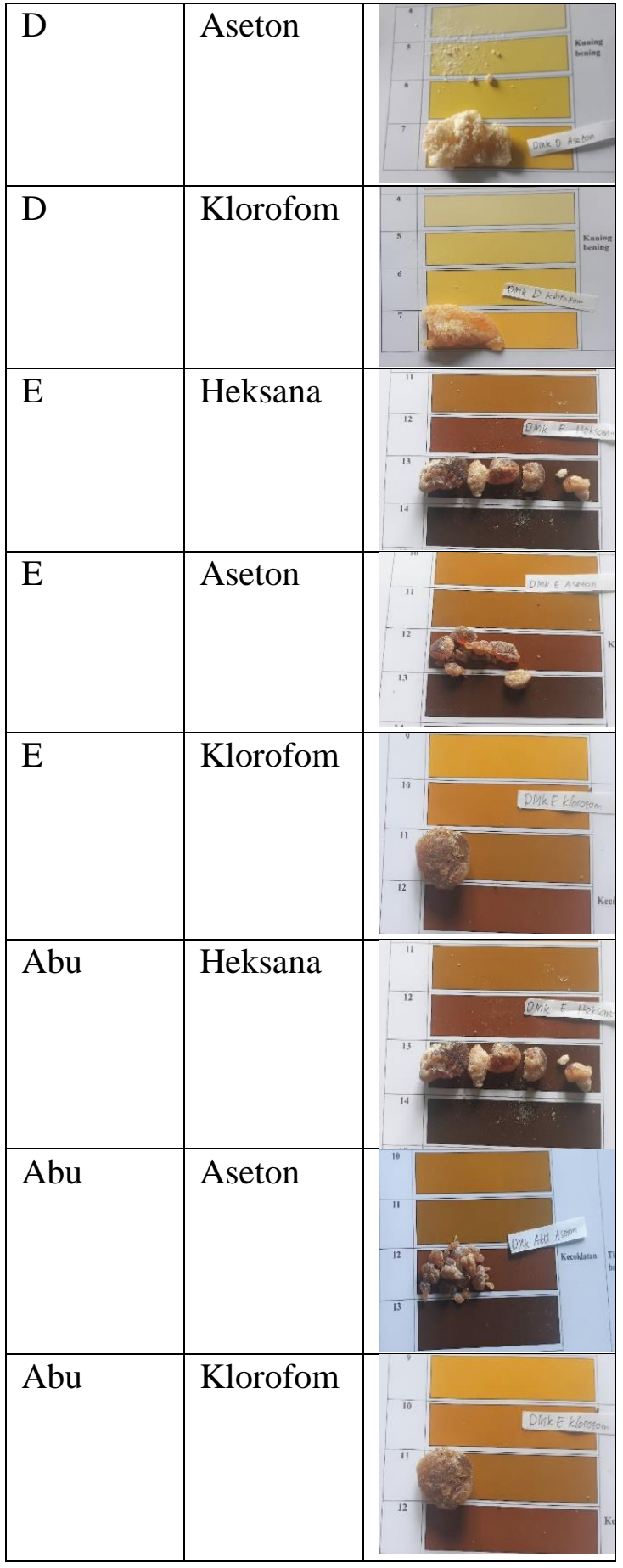

\section{Pembahasan}

\section{Kadar Kotoran}

Damar mata kucing (DMK) kualitas D, E, dan Abu hasil proses pelarutan dilakukan analisis atau uji kadar kotoran yang mana bertujuan untuk diketahuinya kadar kotoran yang berupa kayu, tanah, pasir, dan kotoran organik lainnya. Setelah diamati lebih lanjut dengan dibandingkan dengan data kadar kotoran pada damar referensi yang sudah dibuat dihasilkan kenaikan kelas dari damar tersebut. Dapat dilihat dari tabel di bawah ini

Tabel 16 kenaikan kualitas DMK hasil proses

\begin{tabular}{|c|c|c|c|}
\hline Pelarut & $\begin{array}{l}\text { Kualita } \\
\text { S }\end{array}$ & $\begin{array}{l}\text { Kadar } \\
\text { kotora } \\
\text { n } \\
\end{array}$ & $\begin{array}{l}\text { Kenaika } \\
\text { n } \\
\text { kualitas }\end{array}$ \\
\hline heksana & $\mathrm{D}$ & $0,16 \%$ & $C$ \\
\hline Aseton & $\mathrm{D}$ & $\begin{array}{l}0,146 \\
\%\end{array}$ & C \\
\hline $\begin{array}{l}\text { Klorofo } \\
\mathrm{m}\end{array}$ & $\mathrm{D}$ & $\begin{array}{l}0,012 \\
\%\end{array}$ & $C$ \\
\hline heksana & $\mathrm{E}$ & $0,17 \%$ & C \\
\hline Aseton & $\mathrm{E}$ & $\begin{array}{l}0,164 \\
\%\end{array}$ & C \\
\hline $\begin{array}{l}\text { Klorofo } \\
\text { m }\end{array}$ & $\mathrm{E}$ & $0,07 \%$ & C \\
\hline heksana & Abu & $0,18 \%$ & C \\
\hline Aseton & $\mathrm{Abu}$ & $\begin{array}{l}0,187 \\
\%\end{array}$ & C \\
\hline $\begin{array}{l}\text { Klorofo } \\
\mathrm{m}\end{array}$ & Abu & $\begin{array}{l}0,153 \\
\%\end{array}$ & C \\
\hline
\end{tabular}

Masih terlihat adanya kotoran dalam damar hasil proses terjadi karena kesalahan pada saat proses penimbangan. Sampel yang diuji tidak dilakukan proses pengeringan terlebih dahulu sehingga masih ada beratan kotoran DMK yang terlihat setelah proses.

\section{Kekeruhan dalam Larutan Toluene}

Kekeruhan menunjukkan tingkat kejernihan DMK dalam larutan toluen, kekeruhan dilambangkan dengan satuan NTU(Nephelometric Turbidity Unit). Kekeruhan dipengaruhi oleh sifat padatan yang tersuspensi dalam toluena tersebut. Sifat padatan tersebut mencakup warna dan banyakanya kotoran dari suspensi tersebut. Warna dan banyaknya pengotor mengakibatkan cahaya yang dipancarkan pada saat analisis menuju sampel lebih mudah terpantul karena semakin menggelapnya warna yang dihasilkan. 
Dari data yang didapat klorofom menghasilkan damar yang memiliki nilai kekeruhan paling kecil disaat dilarutkan dalam toluena. Ini disebabkan warna dari damar yang dihasilkan dengan pelarut klorofom menghasilkan warna yang lebih cerah dibandingkan dengan pelarut yang lain. Selain itu penyebab lain dari lebih kecilnya hasil kekeruhan pada damar yang dilarutkan menggunakan pelarut klorofom ialah lebih kecilnya kadar kotoran yang ada di dalamnya. Dapat dilihan pada tabel 4.9.

DMK hasil pemurnian jika dibandingkan nilai kekeruhannya dengan nilai kekeruhan DMK referensi seperti tertera pada beberapa mengalami kenaikan kualitas, terlihat pada tabel dibawah :

Tabel 17 klorofom menghasilkan damar

\begin{tabular}{llll}
\hline $\begin{array}{l}\text { Kualit } \\
\text { as }\end{array}$ & Pelarut & $\begin{array}{l}\text { Kenaikan } \\
\text { kualitas }\end{array}$ \\
\hline D & Heksana & 64,72 & C \\
D & Aseton & 83,89 & C \\
D & Klorform & 54,52 & C \\
E & Heksana & 81,42 & C \\
E & Aseton & 177,72 & TETAP \\
E & Klorform & 76,22 & C \\
Abu & Heksana & 95,02 & C \\
Abu & Aseton & 324,02 & TETAP \\
Abu & Klorform & 102,22 & C \\
\hline
\end{tabular}

Dari tabel diatas terlihat hampir seluruh pelarut dapat menghasilkan kualitas damar yang lebih baik ini disebabkan karena mengurangnya kotoran yang dihasilkan. Walaupun demikian pelarut aseton pada kualitas damar E dan Abu menghasilkan nilai kekeruhan yang relatif sama. Ini disebabkan semakin menggelapnya warna dari damar yang dihasilkan walaupun terjadi pengurangan kadar kotorannya. Sehingga nilai dari kekeruhan relatif tidak berubah kualitasnya.

Bilangan Asam
Bilangan asam merupakan bilangan yang menunjukkan banyaknya asam organik yang terdapat dalam suatu damar.

Terlihat dari seluruh data yang didapatkan bahwa seluruh pelarut mengakibatkan nlai bilangan asam damar yang meningkat. Ini disebabkan karena terbentuknya gugus gugus asam baru ketika proses pemisahan damar dengan pelarut dengan menggunakan proses pemanasan karena adanya proses okidasi gugus gugus aldehid yang ada di dalam damar sehingga terbentuknya gugus asam asam karboksilat. Semakin lama pemanasan semakin tinggi pula nilai bilangan asam yang dihasilkan. Lamanya proses pemanasan di pengaruhi oleh tingkat kelarutan dan titik didih pelarut tersebut. Semakin banyaknya damar yang terlarut pada pelarut semakin lama pula proses pemanasan yang di butuhkan untuk memisahkan damar dengan pelarutnya. Terlihat dari data bahwa klorofom memiliki rendemen yang lebih besar dibandingkan dengan pelarut yang lain sehingga dapat dikatakan bahwa tingkat kelarutan damar dengan pelarut klorofom lebih besar dibandingkan dengan pelarut yang lain. Ini mengakibatkan semakin lamanya proses pemanasan sehingga semakin banyaknya gugus asam yang terbentuk. Terlihat dari tabel di bawah ini menunjukkan bilangan asam terbesar dihasilkan oleh pelarutan damar dengan menggunakan klorofom.

Tabel 18 bilangan asam terbesar dihasilkan oleh pelarutan damar dengan menggunakan klorofom.

\begin{tabular}{cccc}
\hline $\begin{array}{c}\text { Kua } \\
\text { litas }\end{array}$ & Pelarut & $\begin{array}{c}\text { Bilan } \\
\text { gan } \\
\text { asam }\end{array}$ & Ket \\
\hline D & Heksana & 42,07 & $\begin{array}{c}\text { Bilangan } \\
\text { Asam } \\
\text { naik }\end{array}$ \\
D & Aseton & 36,46 & $\begin{array}{c}\text { Bilangan } \\
\text { Asam } \\
\text { naik } \\
\text { Bilangan } \\
\text { Asam } \\
\text { naik }\end{array}$ \\
& Kloroform & 49,08 &
\end{tabular}




\begin{tabular}{|c|c|c|c|}
\hline$E$ & Heksana & 36,46 & $\begin{array}{c}\text { Bilangan } \\
\text { Asam } \\
\text { naik }\end{array}$ \\
\hline $\mathrm{E}$ & Aseton & 28,05 & $\begin{array}{c}\text { Bilangan } \\
\text { Asam } \\
\text { naik }\end{array}$ \\
\hline $\mathrm{E}$ & Kloroform & 49,08 & $\begin{array}{c}\text { Bilangan } \\
\text { Asam } \\
\text { naik }\end{array}$ \\
\hline $\mathrm{Abu}$ & Heksana & 47,68 & $\begin{array}{c}\text { Bilangan } \\
\text { Asam } \\
\text { naik }\end{array}$ \\
\hline $\mathrm{Abu}$ & Aseton & 39,27 & $\begin{array}{c}\text { Bilangan } \\
\text { Asam } \\
\text { naik }\end{array}$ \\
\hline $\mathrm{Abu}$ & Kloroform & 50,49 & $\begin{array}{c}\text { Bilangan } \\
\text { Asam } \\
\text { naik }\end{array}$ \\
\hline
\end{tabular}

\section{Titik Lunak}

Titik leleh dan titik lunak bertujuan untuk mengetahui titik leleh dari dmk hasil pemurnian. Titik leleh dan titik lunak sangat dipengaruhi oleh kadar kotoran dari dmk yang dimurnikan. Semakin tinggi kadar kotoran semakin tinggi pulai nilai titik leleh dan titik lunak dikarenakan energi panas yang dibutuhkan akan lebih besar pada saat damar masih banyak pengotornya.

Dalam penelitian ini didapatkan klorofom menghasilkan dmk dnegan titik lunak dengan nilai terendah dikarenakan nilai dari kadar kotoran dari dmk yang di proses menggunakan klorofom pun menghasilkan nilai yang paling rendah pula. Selain itu pula pada saat proses pemanasan pelarut, klorofom merupakan plearut yang paling sulit di pisahkan. Ini dikarenakan klorofom memiliki tingkat kelarutan terhadap damar lebih besar dibandingkan pelarut yang lain yang dipakai dalam penelitian ini. sehingga setelah proses masih terdapat klorofom yang menghasilkan nilai titik lunak yang rendah pula.

\section{Kadar Abu}

Abu merupakan zat anorganik sisa hasil pembakaran suatu bahan organik. Kadar abu suatu bahan menandakan bahwa bahan tersebut mengandung kotoran dan mineral-mineral lainnya.

Dari tabel 4.13 diketahaui bahwa kadar abu yang dihasilkan paling kecil ialah pelarutan dengan menggunakan pelarut klorofom. Ini disebabkan karena kotoran yang berada di damar hasil pelarutan dengan pelarut klorofom kurang dari kadar kotoran yang ada di damar hasil pelarutan dengan pelarut yang lain. Menurunnya kadar abu menunjukkan bahwa proses pemurnian berhasil terutama pada tahapan pelarutan, dimana kotoran dan mineral yang ada pada DMK terpisah karena DMK larut dengan pelarut sehingga ketika dilakukan proses penyaringan pengotor tertahan di atas saringan.

Kadar abu DMK hasil pemurnian semuanya lebih rendah dibandingakan kadar abu DMK referensi, dan jika ditinjau kenaikan kualitas DMK hasil pemurnian dengan kadar abu DMK dan jika ditinjau kenaikan kualitas DMK hasil pemurnian dengan kadar abu DMK maka akan diketahui kenaikanya pada tabel dibawah:

Tabel 19 kenaikan kualitas DMK hasil pemurnian dengan kadar abu.

\begin{tabular}{llll}
\hline $\begin{array}{l}\text { Kuali } \\
\text { tas }\end{array}$ & $\begin{array}{l}\text { Jenis } \\
\text { Pelarut }\end{array}$ & $\begin{array}{l}\text { Kadar } \\
\text { abu }\end{array}$ & $\begin{array}{l}\text { Kenaik } \\
\text { an }\end{array}$ \\
\hline D & Heksana & $6,67 \%$ & $\mathrm{C}$ \\
D & Aseton & $5,38 \%$ & $\mathrm{~A}$ \\
D & Klorofom & $5,06 \%$ & $\mathrm{~A}$ \\
E & Heksana & $6,93 \%$ & $\mathrm{C}$ \\
E & Aseton & $7,42 \%$ & $\mathrm{C}$ \\
E & Klorofom & $5,27 \%$ & $\mathrm{~A}$ \\
Abu & Heksana & $7,23 \%$ & $\mathrm{C}$ \\
Abu & Aseton & $8,75 \%$ & $\mathrm{C}$ \\
Abu & Klorofom & $6,61 \%$ & $\mathrm{~A}$ \\
\hline
\end{tabular}


Terlihat dari tabel bahwa semuanya mengalami kenaikan kualitas dalam hal kadar abu, dimana kenaikannnya cukup signifikan ialah dengan pelarut klorofom pada semua jenis DMK yang diteliti ( D,E,dan Abu ). Namun pelarut yang kurang memberikan kenaikan yang paling kecil ialah pelarut heksana pada seluruh jenis DMK. Namun jika dilihat dari kenaikan nilai dari masing masing percobaan dapat dilihat bahwa metode pelarutan efektif meningkatkan kadar abu dari masing masing DMK.

\section{Analisis Warna menggunakan Referensi Warna}

Analisis warna bertujuan untuk mengetahui golongan DMK hasil pemurnian dengan cara mencocokkan dengan referensi warna, jadi akan diketahui tingkatan warna DMK hasil pemurnian. Jika dibandingakan dengan analisis DMK referensi, maka akan didapat data pada tabel berikut :

Tabel 20 hasil analisis/uji warna

\begin{tabular}{lllll}
\hline Kualitas & Pelarut & Golongan warna & Kualitas & $\begin{array}{l}\text { Perbandingan } \\
\text { terhadap } \\
\text { refferesi }\end{array}$ \\
\hline D & Heksana & Kuning bening & Bagus & Menurun \\
D & Aseton & Kuning bening & Bagus & Menurun \\
D & Klorofom & Kuning bening & Bagus & Menurun \\
E & Heksana & Caklat & Bagus & Menurun \\
E & Aseton & Cokklat & Bagus & Menurun \\
E & Klorofom & Coklat & Bagus & Menurun \\
Abu & Heksana & Caklat & Tidak bagus & Menurun \\
Abu & Aseton & Coklat & Tidak bagus & Menurun \\
Abu & Klorofom & Caklat & Tidak bagus & Menurun \\
\hline
\end{tabular}

Terlihat dari hasil proses seluruh jenis damar dari semua jenis pelarut mengalami penurunan dalam hal warna. Ini di sebabkan karena adanya proses yellowing pada saat penguapan solvent. Proses yellowing terjadi akibat terjadinya kerusakan struktur permukaan damar ketika adanya proses pemanasan. Terjadinya pemanasan terjadi ketika adannya proses oksidasi senyawa terpen yang ada di dalam DMK. Proses oksidasi pada senyawa terpen akan menghasilkan penggelapan pada DMK tersebut. Senyawa terpen merupakan senyawa senyawa yang ada di dalam damar, seperti germacrene D. Bukti germacrene teroksidasi ialah dengan timbulnya senyawa senyawa hasil oksidasi dari germacrene D. Contoh dari senyawa hasil proses oksidasi tersebut ialah germacrene D-ol senyawa alkohol yang merupakan dari senyawa alkana germacrene D.

\section{Peningkatan Golongan Kualitas DMK Hasil Pemurnian secara Final}

Setelah dilakukan analisis, dan sudah diketahui kenaikan kualitas dmk ditiap analisis maka dapat dibuat kenaikan dmk hasil proses secara final dalam tabel dibawah ini.

Tabel 21 Peningkatan golongan kualitas DMK Hasil Pemurnian secara Final

\begin{tabular}{|c|c|c|c|c|c|c|c|c|}
\hline $\begin{array}{c}\text { Kualitas } \\
\text { Damar }\end{array}$ & $\begin{array}{l}\text { Jenis } \\
\text { Pelarut }\end{array}$ & $\begin{array}{c}\text { Kadar } \\
\text { Kotoran }\end{array}$ & $\begin{array}{l}\text { Bilangan } \\
\text { Asam }\end{array}$ & $\begin{array}{c}\text { Kekeruhan } \\
\text { dalam } \\
\text { Toluena }\end{array}$ & $\begin{array}{c}\text { Titik } \\
\text { Lunak }\end{array}$ & $\begin{array}{c}\text { Kadar } \\
\text { Abu }\end{array}$ & $\begin{array}{l}\text { Analisis } \\
\text { Warna }\end{array}$ & $\begin{array}{c}\text { Kualitas } \\
\text { Final }\end{array}$ \\
\hline $\mathrm{D}$ & Heksana & $\mathrm{C}$ & Meningkat & $\mathrm{C}$ & $\mathrm{A}$ & $\mathrm{C}$ & Menurun & $\mathrm{C}$ \\
\hline D & Aseton & $\mathrm{C}$ & Meningkat & $\mathrm{C}$ & A & A & Menurun & C \\
\hline D & Kloroform & $\mathrm{C}$ & Meningkat & $\mathrm{C}$ & A & A & Menurun & $\mathrm{C}$ \\
\hline E & Heksana & $\mathrm{C}$ & Meningkat & C & C & C & Menurun & C \\
\hline E & Aseton & $\mathrm{C}$ & Meningkat & TETAP & A & C & Menurun & E \\
\hline E & Kloroform & $\mathrm{C}$ & Meningkat & C & A & A & Menunun & C \\
\hline $\mathrm{ABU}$ & Heksana & $\mathrm{C}$ & Meningkat & C & $\mathrm{C}$ & C & Menurun & $\mathrm{C}$ \\
\hline $\mathrm{ABU}$ & Aseton. & $\mathrm{C}$ & Meningkat & TETAP & A & C & Menurun & $\mathrm{Abu}$ \\
\hline$\underline{\mathrm{ABU}}$ & Kloroform & C & Meningkat & $\mathrm{C}$ & $\mathrm{A}$ & $\mathrm{A}$ & Menurun & $\mathrm{C}$ \\
\hline
\end{tabular}

Analisis GC-MS dilakukan untuk mengetahui komposisi DMK murni kelas A dan DMK hasil analisis terbaik jika dilihat dari segi peningkatan kualitas. Ditetapkan DMK kualitas D dengan pelarut kloroform merupakan DMK hasil terbaik.

Analisis ini mendapatkan data sebagai berikut

Berikut gambar hasil analisis GC-MS DMK A referensi dan DMK D dengan pelarut kloroform. 


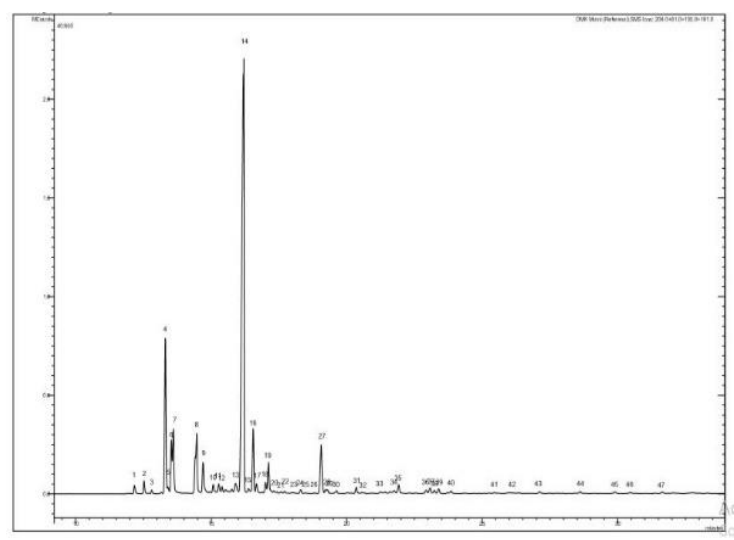

Gambar 1 hasil analisis GC-MS dmk A referensi

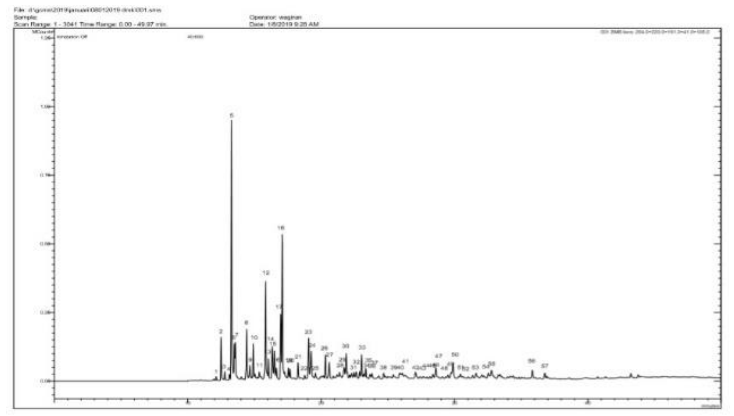

Gambar 2 hasil analisis GC-MS DMK D dengan pelarut kloroform

Dari data yang sudah didapatkan terlihat bahwa banyak komponen komponen DMK murni yang tidak terdapat pada tabel komponen DMK yang sudah di murnikan. Ini terjadi karena adanya perubahan bentuk dari komponen komponen DMK murni setelah dimurnikan dengan metode yang dilakukan.

Germacrene D merupakan komponen terbanyak yang ada pada di DMK murni tetapi menjadi tidak terlihat pada tabel komponen DMK yang sudah dimurnikan. Hal inin terjadi karena Germacrene D mengalami proses penguraian selama proses. Penguraian tersebut terjadi dikarenakan adanya proses pemanasan dan suasana asam yang di akibatkan oleh proses pemanasan itu sendiri. Pada suasana asam Germacrene D akan berurai menjadi $\beta-$ copaane , $\alpha$-elemene, $\beta$ -

elemene, $\gamma$-mourollene dengan komposisi yang ada. Selain itu dengan ada hamparan sinar Gemacrene D juga terurai menjadi $\beta$-bourbone. Semua senyawa produk turunan tersebut ada pada tabel komponen DMK hasil pemurnian.

Selain itu proses pemanasan menghasilkan proses oksidasi yang mengakibatkan berubahnya komponen DMK. Komponen Gemacrene D akan mudah teroksidasi menjadi bentuk alkohol dan akan teroksidasi seterusnya menjadi bentuk aldehid, asam karboksilat, dan keton. Hal ini dapat dilihat dari adanya senyawa gugus alkohol, aldehid, asam karboksilat, dan keton yang baru terbentuk pada saat setelah proses pemurnian.

Sehingga bisa diberi kesimpulan, metode yang digunakan dapat merubah komponen komponen yang ada di dalam DMK.

\section{KESIMPULAN}

1. Pemurnian DMK dengan metode pelarutan dengan semua jenis pelarut sangat efektif untuk menghilangkan kotoran yang ada dalam DMK.

2. Berdasarkan dari hasil analisis klorofom merupakan pelarut paling aktif untuk meningkatkan kualitas dari DMK. Terlihat dari hasil analisis Kadar abu, kadar kotoran, dan kekeruhan dalam toluene DMK yang dilarutkan menggunakan pelarut klorofom menghasilkan kenaikan yang signifikan dibandingkan dengan pelarut lainnya. Selain itu nilai rendemen dari DMK yang dilarutkan menggunakan kloroform merupakan yang terbesar dibandingkan DMK yang dilarutkan dengan pelarut Aseton dan Hexana.

3. DMK yang didapat mengalami kenaikan bilangan asam, penggelapan warna dikarenakan proses pemanasan yang menghasilkan perubahan komposisi pada permukaan damar selama proses pemanasan. Ini mengakibatkan timbulnya radikal radikal bebas yang mengakibatkan terjadinya proses oksidasi sehingga 
terjadi penggelapan warna dan peningkatan bilangan asam.

4. DMK hasil proses pemurnian mengalami perubahan secara kimia. Ini terjadi karena adanya proses reanggarement pada komponen penyusun DMK asli yaitu Germacrene D ketika proses dipanaskan untuk penguapan pelarut yang digunakan.

5. Kualitas DMK belum dapat dikatakan sesuai dengan standar SNI 2900.12012 dan SNI 2900.2-2013

\section{Saran}

Penambahan bahan antioksidan dalam proses pemanasan untuk mencegah terjadinya proses oksidasi.

Pada saat penimbangan kadar kotoran harus dilakukan adanya proses pengeringan.

\section{DAFTAR PUSTAKA}

Badan Perencanaan Pembangunan Daerah Kabupaten Pesisir Barat. 2015 . Profil Investasi Berbasis Klaster Kabupaten Pesisir Barat Tahun 2015. Krui : Jl. Kesuma No. 09.

Edriana, E., Dahlian, E \& Sumadiwangsa, E.S. 2004. Teknik pembuatan pernis dari damar untuk usaha kecil. Jurnal Penelitian Hasil Hutan 22(4): 205-213.

E. René de la Rie. 2014. Photochemical and Thermal Degradation of Films of Dammar Resin.

Fintina, L. 2007 . Pemurnian Beberapa Mutu Damar Mata Kucing (Shorea javanica) dengan Sistem Pemanasan. [skripsi]. Bogor: Departemen Hasil Hutan, Fakultas Kehutanan, Institut Pertanian Bogor.

Gusti ,R. Esa Pangersa . Zulnely . 2014.SIFAT FISIKO KIMIA DAMAR

$\begin{array}{lr}\text { MATA KUCING } & \text { HASIL } \\ \text { PEMURNIAN } & \text { TANPA } \\ \text { PELARUT(Physico } & \text { Chemical } \\ \text { Properties of Purified Mata Kucing } & \text { Kammar Without Solvent). Bogor: Pusat } \\ \text { Dambang Keteknikan Kehutanan dan } \\ \text { Litbang Kengolahan Hasil Hutan. }\end{array}$

Lakerveld \& A van 2007. Price Determination and Upgrading Within the Damar Trade Chain. Tesis Pasca Sarjana. Amsterdam: International Development Studies.

Namiroh, N. 1998. Pemurnian Damar (Shorea javanica) dengan Kombinsi Pelarut Organik. [skripsi]. Bogor: Fakultas Teknologi Pertanian, Institut Pertanian Bogor.

Sari, Rita K. Dkk.2012. Karakterisasi Damar Mata Kucing dalam Rangka Revisi Standar Nasional Indonesia (Characterization of Cat's Eye Dammar for Revision of Indonesia National Standard). Bogor: Puslitbang Keteknikan Kehutanan dan Pengolahan Hasil Hutan, Kementerian Kehutanan, Jl. Gunung Batu No. 5, Bogor 16680.

Setyaningsih, N. 1992. Pemurnian Damar (Shorea javanica) dengan Menggunakan Pelarut Organik dan Bahan Pemucat. [skripsi]. Bogor: Fakultas Teknologi Pertanian, Institut Pertanian Bogor.

Sumadiwangsa, E.S \& Gusmailina. 2006. Teknologi Budidaya, Pemanfaatan dan Pengembangan Hasil Hutan Bukan Kayu.Bogor.

Zulnely, A. Hakim dan Nurma W. 1994.Karakteristik Damar dan Pemanfaatannya. Makalah Penunjang pada Diskusi Hasil Penelitian Hasil Hutan. Bogor. 